\title{
Comparison of the Effects of Vasectomy and Experimental Cryptorchidism in Rats: I. Testicular Histology
}

\author{
By \\ GÜNAY Yasemin, BULUT Hüseyin Eray, ONARLIOGLU Bilge and \\ BAŞIMOGLU-KOCA Yücel
}

Department of Histology - Embryology, Faculty of Medicine, Cumhuriyet University, Sivas, TURKEY

- Received for Publication, April 3, 1998 -

\begin{abstract}
Key Words: Vasectomy, Cryptorchidism, Testes, Rat, Histology
Summary: The effects of cryptorchidism, one of the most important congenital malformations resulting with the defects in testicular structure thus infertility, is the best known subject in male reproduction. Those best known effects make the usage of cryptorchidism as a second control criteria when the effects of other male infertility reasons are attempted to be determined. Therefore the persistency or reversibility of the effects of vasectomy on testicular structure have been compared to the testicular features following experimental cryptorchidism and to the control group findings. To do this, rats were divided into 3 groups. While the control group animals were sham operated, the experimental group animals were undergone either vasectomy or experimental cryptorchidism procedures. Testicular histology of the control and experimental groups was determined using convenient staining methods at the light microscopical level.

The comparison of the findings from the control and experimental groups showed that the testicular features of the vasectomized group were similar to those seen in the control group in contrast to the experimental cryptorchidism group which had irreversible testicular alterations. Results of the present study indicated the convenience of the usage of vasectomy in male contraception.
\end{abstract}

Although its application rate is low, vasectomy is still an important method for male contraception. Early and late period complications and debates on the reversibility of the effects of vasectomy in testicular morphology and function are the main reasons for its low application rate (Kendrick et al., 1985; Flickinger et al., 1990).

Cryptorchidism is a congenital malformation causing permanent infertility via its effects on testicles and genital tract. The persistent effects of cryptorchidism could be used as the testing criteria which may help to make interpretations about the effects of vasectomy on testicular structure. Therefore in the present study, experimental cryptorchidism was used as a permanent infertility model, and findings of the vasectomized groups were compared to both control and experimental cryptorchidism groups.

\section{Materials and Methods}

Fifteen 2 months old male Swiss albino rats, $125-150 \mathrm{~g}$ of weight, were used in the present study. While 5 rats were sham operated (control group), the rest were divided into two groups each of which consisting of 5 rats. First group rats were vasectomized unilaterally. To do this, rats were anaesthetised by ether inhalation. The operation was performed under aseptic conditions through a vertical midline abdominal incision. Each vas deferens was divided between two silk ligatures approximately $1.5 \mathrm{~cm}$ proximal to the end of the vas. Second group was undergone unilateral experimental cryptorchidism by fixing the right testicle of each animal onto the abdominal wall. Following 3 months of experimental period, sham operated, vasectomized and cryptorchid rats were killed, and ipsilateral and contralateral testicles of each animal were obtained by laparotomy. Testicular tissues were fixed in Bouin's solution, dehydrated through the in- 
creasing concentrations of ethanol and embedded in paraffin. $4-5 \mathrm{~mm}$ thick paraffin sections were cut and stained using either haematoxylene-eosin or Mallory-azan staining methods.

\section{Results}

\section{Control group}

Control group rat testicular sections showed characteristic spermatogonia A and B cells with their dark stained nuclei on the seminiferous tubule basement membrane. Spermatocytes and spermatids seemed to locate on the spermatogonia B whereas the mature sperms filled the tubular lumen. There were also irregular shaped Sertoli cells among the spermatocytes extending from the basement membrane through the lumen.

Myoid cells, fibroblasts and Leydig cells were seen in the interstitial tissue filling the space between seminiferous tubules (Fig. 1).

\section{Experimental cryptorchidism group}

Following 3 months of experimental cryptorchidism, ipsilateral rat testicular morphology showed completely atrophic seminiferous tubules and increased interstitial connective tissue (Fig. 2a). Atrophic seminiferous tubules had thickened basal lamina, and irregular spermatogonia and spermatocyte series were observed in the seminiferous tubules which were totally collapsed. Therefore no mature sperms were found in the tubule lumen (Fig. 2b). In addition, inflammatory cell infiltration (Fig. 2b) and collagen accumulation (Fig. 2c) were also evident in the interstitial connective tissue. Three months after experimental cryptorchidism, testicular tubular features of the contralateral testicles were similar to those seen in the control group whereas an increased stromal oedema was found in the interstitial tissue of the rat testis (Fig. 3).

\section{Vasectomy group}

Three months after unilateral cryptorchidism, ipsilateral rat testicular tissue demonstrated spermatogonial cell lining in normal structure, tubular lumen filled with mature sperms. However, some of the seminiferous tubules underwent atrophy and lost their normal cellular structures. While no inflammatory cells were observed, distinctive oedema was evident in the interstitium (Fig. 4a,b). Contralateral testicular features, following three months of vasectomy, were similar to those seen in the control group. These were seminiferous tubules containing characteristic spermatocyte cell lining along with mature sperms taking place in the lumen. In addition, there were no histopathological findings in the interstitial tissue of the contralateral testis (Fig. 5).

\section{Discussion}

Cryptorchidism is the undescent of the testicles from abdominal cavity into the scrotum which occurs in decreasing rates from infantile life to the maturity, and it is one of the main male infertility reasons.

Vasectomy is the most effective and reliable method used in the male contraception. However, the general usage of vasectomy has been demonstrated to be less than female contraception in the world (Kendrick et al., 1985) since vasectomy may cause trauma, pain, haematome and infection risk during early periods and may cause chronic testicular pain and functional alterations during late periods.

Reversibility of the effects of vasectomy has always been under discussion. Although the vasovasostomy could reverse the anatomical structure of testicles, the fertility rate following vasovasostomy was still low (Flickinger et al., 1990a). Therefore the present study aimed to investigate the effects of vasectomy by comparing the testicular features with the normal and cryptorchid rat testis histology which was used as a permanent infertility model.

The ipsilateral testicular morphology following experimental cryptorchidism showed defects such as atrophic seminiferous tubules along with thickened basal lamina and irregular spermatocyte lines and increased interstitial tissue among the tubules.

Jones and co-workers (1977) suggested a more defective germinal epithelium than the interstitial tissue in rats following experimental cryptorchidism. In addition, a previous study on the effects of bilateral cryptorchidism on testicular function showed germinal epithelial defects and hypertrophic Leydig cells in the interstitium (Lunstra et al., 1988). Similar findings were observed by several investigators. These were defects in germinal epithelial structures which could indicate a failure in spermiogenic activity and a particular fibrosis of the interstitium in ipsilateral testicles of the cryptorchid rats (Hgenas et al., 1978; Schindler et al., 1982; Foresta et al., 1996).

It has been suggested that the intratesticular concentrations of testosterone could play a more important role in spermiogenic activity than the serum concentrations (Hgenas et al., 1978). Comparison of the interstitial fluid testosterone levels between normal and cryptorchid rats demonstrated that cryptorchid animals had twice as much testo- 
sterone levels (Hgenas et al., 1978). This may indicate that the defects in seminiferous tubules could be developed independent of the intratesticular testosterone levels.

Basement membrane hyalinization, increased numbers of myoid cells and fibrosis developing with the collagen accumulation under the effects of cryptorchidism were suggested to be the main reasons for germinal epithelial atrophy (Nistal and Paniagua, 1984). In addition, defects in spermatids could possibly occur as a result of an interruption in the manchette microtubular system via depolimerization of the microtubular subunits. However, it is not clear whether this microtubular depolimerization occur under the effects of increased intratesticular temperature or not.

Sertoli cells have a still unclear relationship with germinal epithelial cells. They also take place in the protection of blood-testis barrier. It has been shown that the Sertoli cell structure and function were changed after experimental cryptorchidism (Vitale et al., 1973). This altered function of Sertoli cells may also effect the spermiogenic activity of testicles.

While no adverse effects of unilateral vasectomy were found in the contralateral site, ipsilateral testicular histology seemed to be affected in the present study. There were both normal and atrophic seminiferous tubules which had irregular spermiogenic cell lines and oedema in the interstitial tissue. Similar findings were suggested by several previous studies (Kendrick et al., 1985; Flickinger et al., 1990b; Sun et al., 1992; McDonald et al., 1996).

Flickinger and co-workers (1990) showed the germinal epithelial features by tubule score counting method, and these were similar to those seen in the present study. In the first and second months following vasectomy, rat testicles were suggested to have distinctive morphological features reflecting the adverse effects of vasectomy, however, the testicular features were similar to the control group testicular structure during the third month of vasectomy (Flickinger et al., 1990a). In addition, they did not observe inflammatory cell infiltration into the testicular interstitium (Flickinger et al., 1990a) which was also consistent with the findings of the present study. In conclusion, testicular atrophy was suggested by almost every previous study dealing with the effects of vasectomy, and that was also the main feature of the testicular alterations after vasectomy found in the present study.

Testicular alterations after vasectomy were suggested to occur under the direct effects of antisperm antibodies (Herr et al., 1987). Following experimental allergic orchitis in guinea pigs, testicular findings such as exfoliation of germinal epithelium into the lumen, degenerated spermatids and interstitial fibrosis supported the hypothesis that antisperm antibodies are directly involved in these testicular alterations (Tung et al., 1980). Testicular features occurring after the experimental autoimmun reactions were similar to those seen in the vasectomized animals, indicating that the antisperm antibodies may play a crucial role in those testicular changes related to the vasectomy.

The present study attempted to investigate the structural changes after vasectomy, and comparisons were made between the vasectomized group, experimental cryptorchidism group and the control group. Although there have been discrepancies between the results of previous studies on this subject, it has been clearly shown that the effects of vasectomy could be reversed after a certain time period. On the other hand, experimental cryptorchidism has been suggested to be a permanent infertility reason. In conclusion, it could be postulated that the vasectomy is a convenient method for male contraception.

\section{References}

1) Flickinger JC, Herr JC, Howard SS, Sisak JR, Janice ME, Fusia TJ, Vailes LD and Handley HH. Testicular changes after vasectomy and vasovasostomy in Lewis rats. Anat Rec 1990a, 227:37-46.

2) Flickinger CJ, Herr JC, Caloras D, Sisak JR and Howards SS. Inflammatory changes in the epididymis after vasectomy in the Lewis rats. Biol Reprod 1990b; 43:34-45.

3) Foresta C, Ferlin A, Garolla A, Milani C, Oliva G and Rossato M. Functional and cytologic features of the contralateral testis in cryptorchidism. Fertil Steril 1996; 66: 624-629.

4) Herr JC, Flickinger CJ, Howard D, Caloras ES, Yarbrou ES, Spell DR and Gallien TN. The relation between antisperm antibodies and testicular alterations after vasectomy and vasovasostomy in Lewis rats. Biol Reprod 1985; 37: 1297-1305.

5) Hgenas L, Ritzen EM and Suginami H. Hormonal milieu of the seminiferous tubules in the normal and cryptorchid rat. Int J Androl 1978; 1:477-484.

6) Jones TM, Anderson W, Fang VS, Landau RL and Rosenfield RL. Experimental cryptorchidism in adult male rats: Histological and hormonal sequelae. Anat Rec 1977; 189: 1-28.

7) Kendrick JS, Rhodenhiser EP, Rubin GL and Greenspan JR. Characteristics of vasectomies performed in selected outpatient facilities in the United States. J Reprod Med 1985; 30:396.

8) Lunstra DD and Schanbacher BD. Testicular function and Leydig cell ultrastructure in long term bilaterally cryptorchid rams. Biol Reprod 1988; 38:211-220.

9) Mc Donald SW, Lockhart A, Gormal P and Bennett NK. Changes in the testes following vasectomy in the rat. Clin Anat 1996; 9:296-301.

10) Nistal $M$ and Paniagua $R$. Testicular and epididymal pathology. Thieme, Stralton Inc. New York, 1984.

11) Schindler AM, Diaz P, Cuendent A and Sizonenko PC. 
Follicle - stimulating hormone. IV. Study of the histology of pubertal cryptorchid and scrotal testes in relation to the secretion of gonadotropins. Fertil Steril 1982; 37:828-836.

12) Sun YB, Qiu $Y$ and Wang ZX. Vasectomy and spermatic granuloma in hamsters. Contraception 1992; 45:177-185.

13) Tung KSK, Unanve HR and Dickson FJ. The immuno- pathology of experimental allergic orchitis. Am J Pathol 1980; 60:313-328.

14) Vitale $R$, Fawcet DW and Dym $M$. The normal development of the blood-testis barrier and the effects of clomiphene and estrogen treatment. Anat Rec 1978; 176:333344. 
Plate I

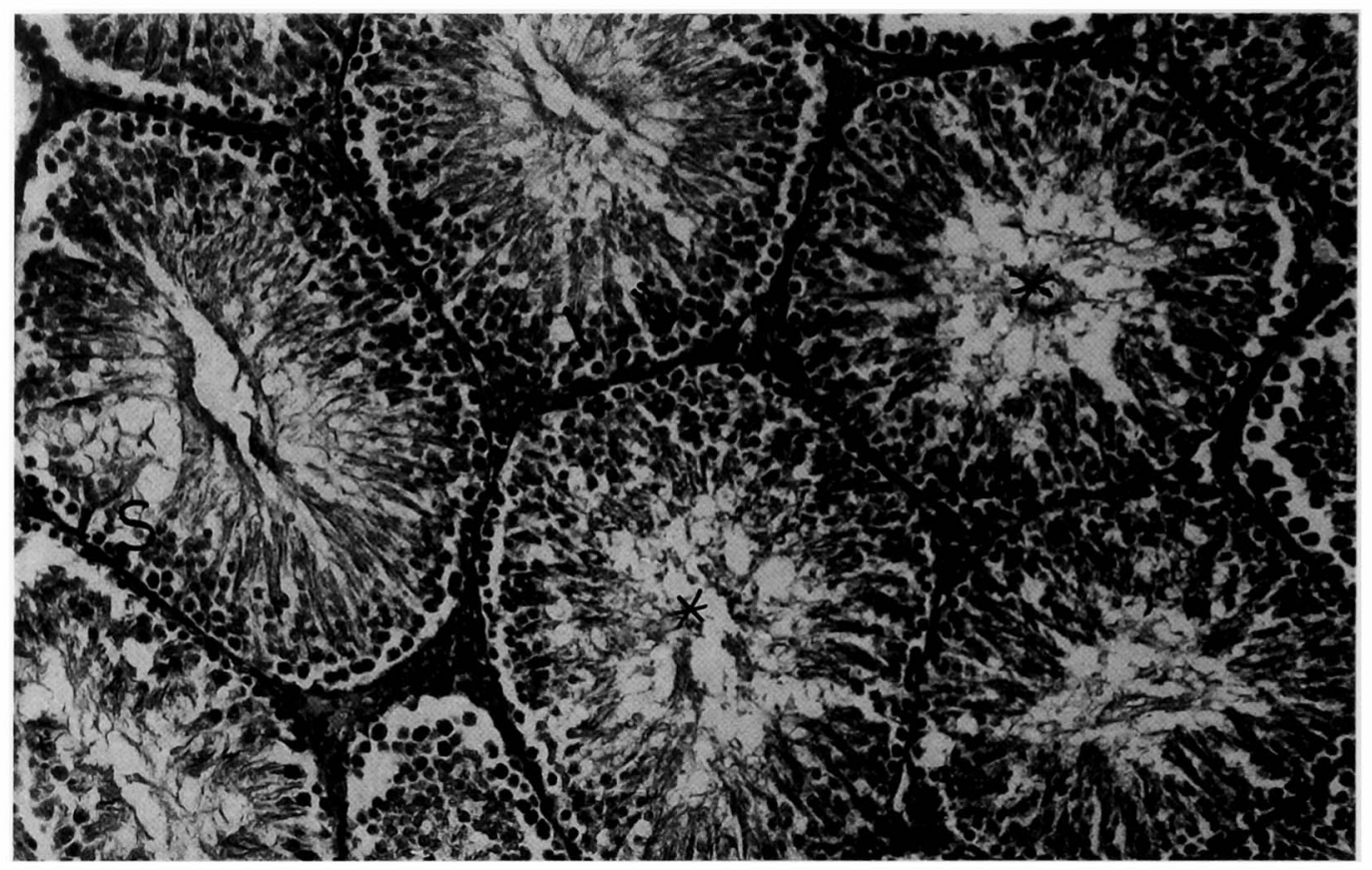

\section{Explanation of Figures}

\section{Plate I}

Fig. 1. Shows the control group seminiferous tubular features in rat testicles. These tubular features are spermatogonia A $(\rightarrow)$ and B $(\Rightarrow)$, spermatocyte series (spt), Sertoli cells (S) and mature sperms $\left(^{*}\right)$ in the lumen. Interstitium (I). $\times 350$, haematoxylene eosin. 
Plate II

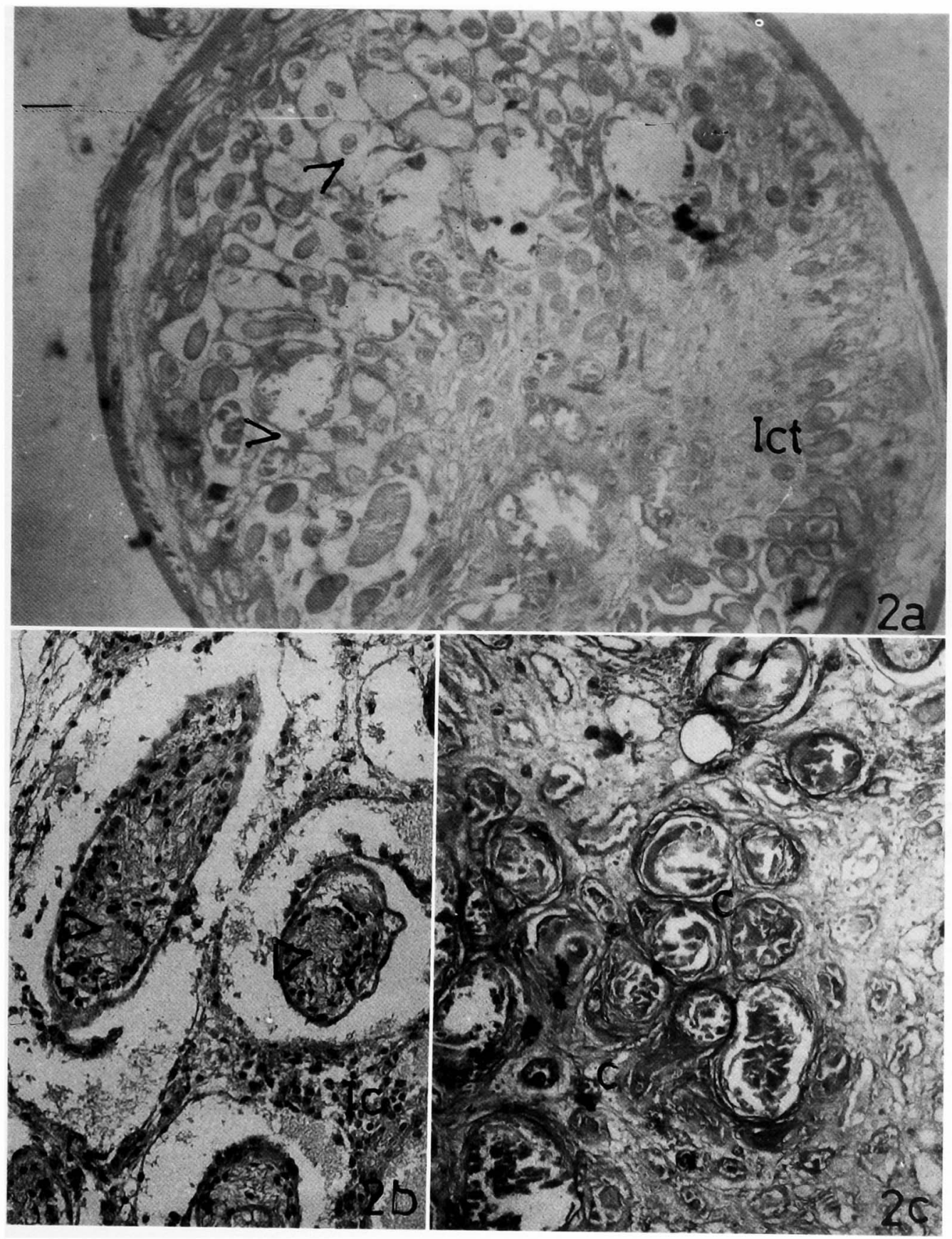

\section{Plate II}

Fig. 2. a: Experimental cryptorchidism group testicular structure has atrophic seminiferous tubules ( $>$ ) and increased interstitial connective tissue (Ict). $\times 35$, haematoxylene - eosin.

b: Germinal epithelial cells $(\triangleright)$ seem degenerated in the atrophic seminiferous tubules $(>)$ which also has thickened basal lamina. Inflammatory cell (Ic) infiltration is seen in the interstitium. $\times 350$, haematoxylene - eosin.

c: Increased collagen accumulation $\left({ }^{*}\right)$ is demonstrated by special staining methods. $\times 170$, Mallory - azan. 
Plate III

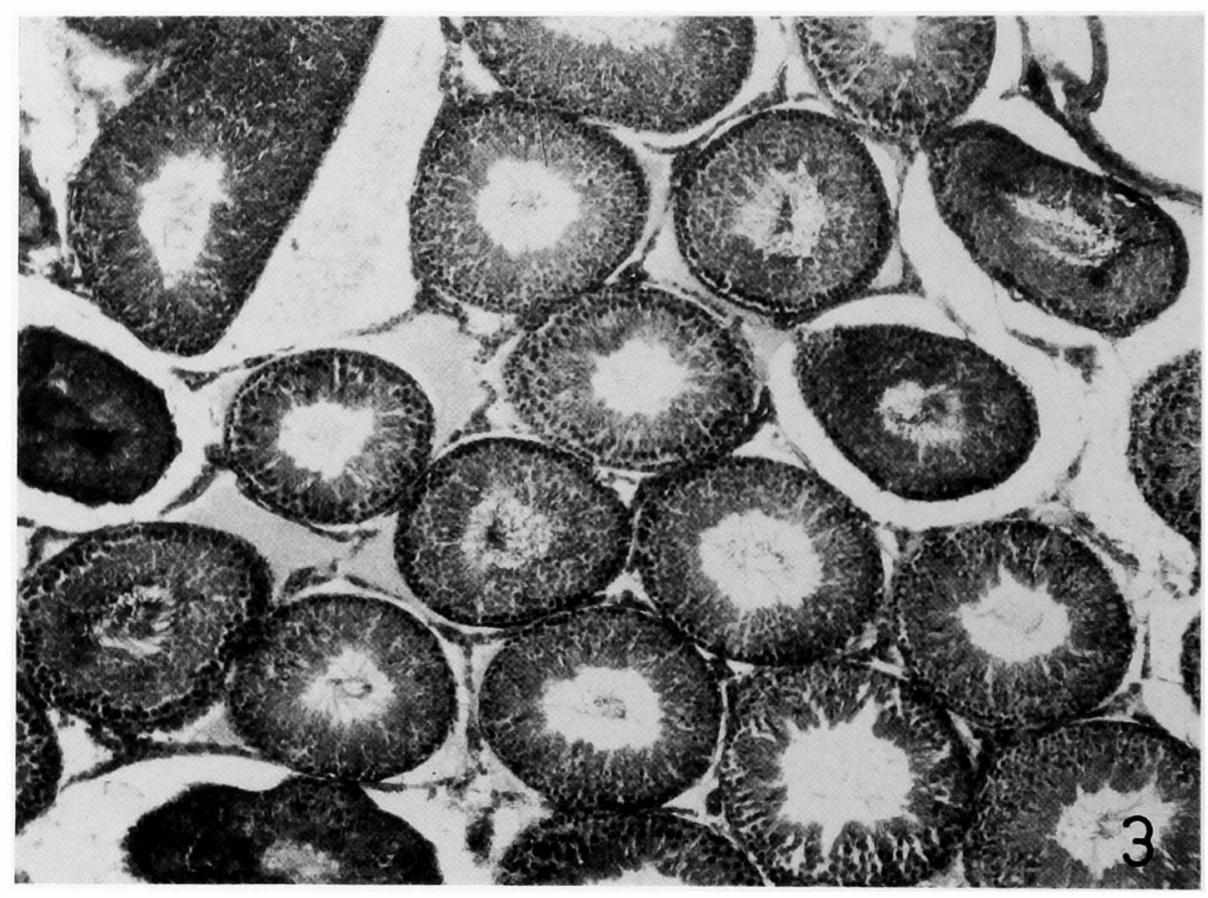

Plate III

Fig. 3. Shows the contralateral testicular morphology following three months of experimental cryptorchidism. Structures of seminiferous tubules and interstitial tissue are similar to those observed in the control group. $\times 350$, haematoxylene - eosin. 
Plate IV
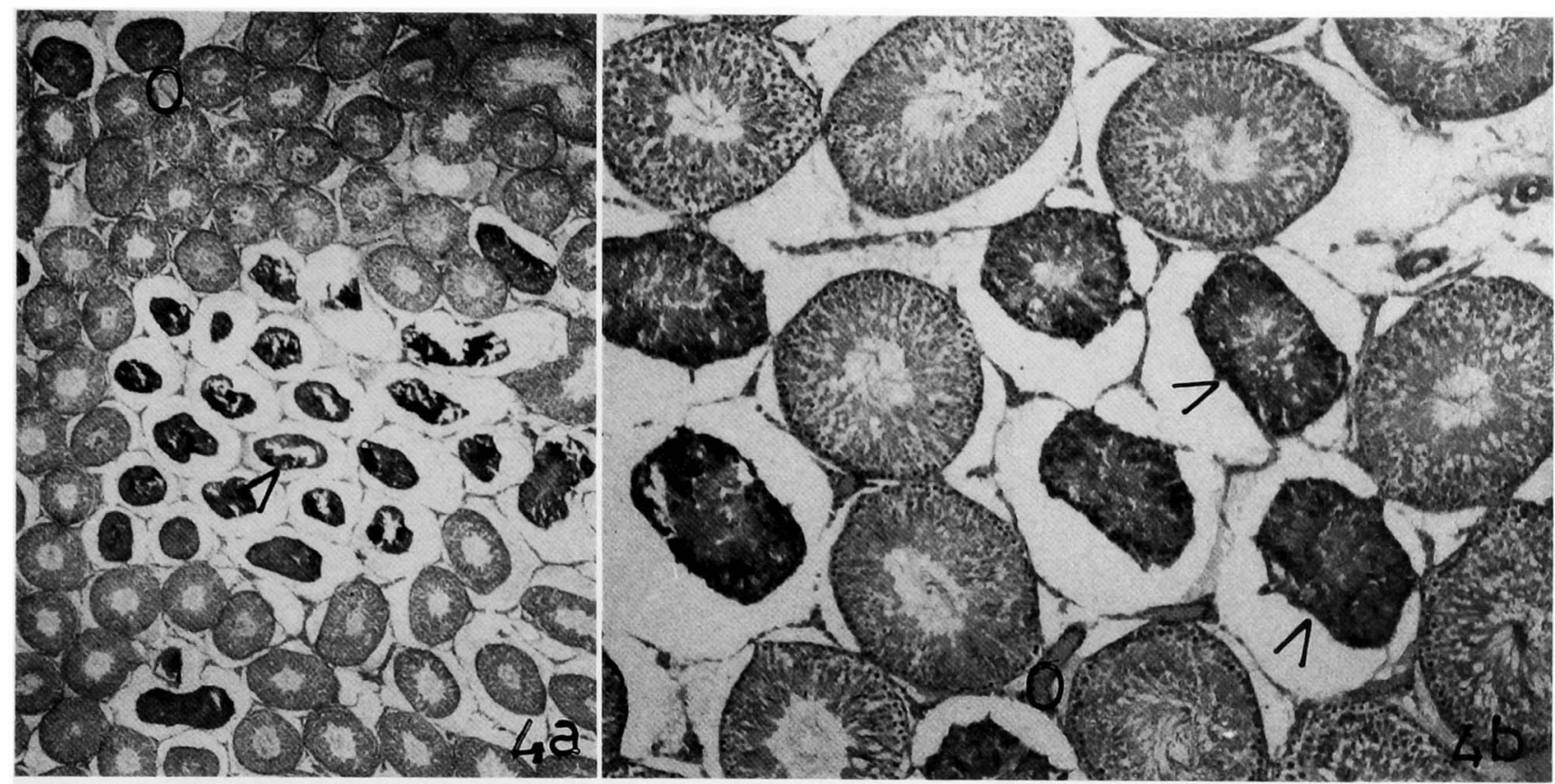

Plate IV

Fig. 4. a, b: Three months after vasectomy, ipsilateral testicular morphology demonstrates normal seminiferous tubules and atrophic tubules $(>)$ scattered among the normal ones. Interstitial oedema $(O)$ is also evident. a: $\times 170$, haematoxylene - eosin. b: $\times 350$, haematoxylene - eosin. 
Plate V

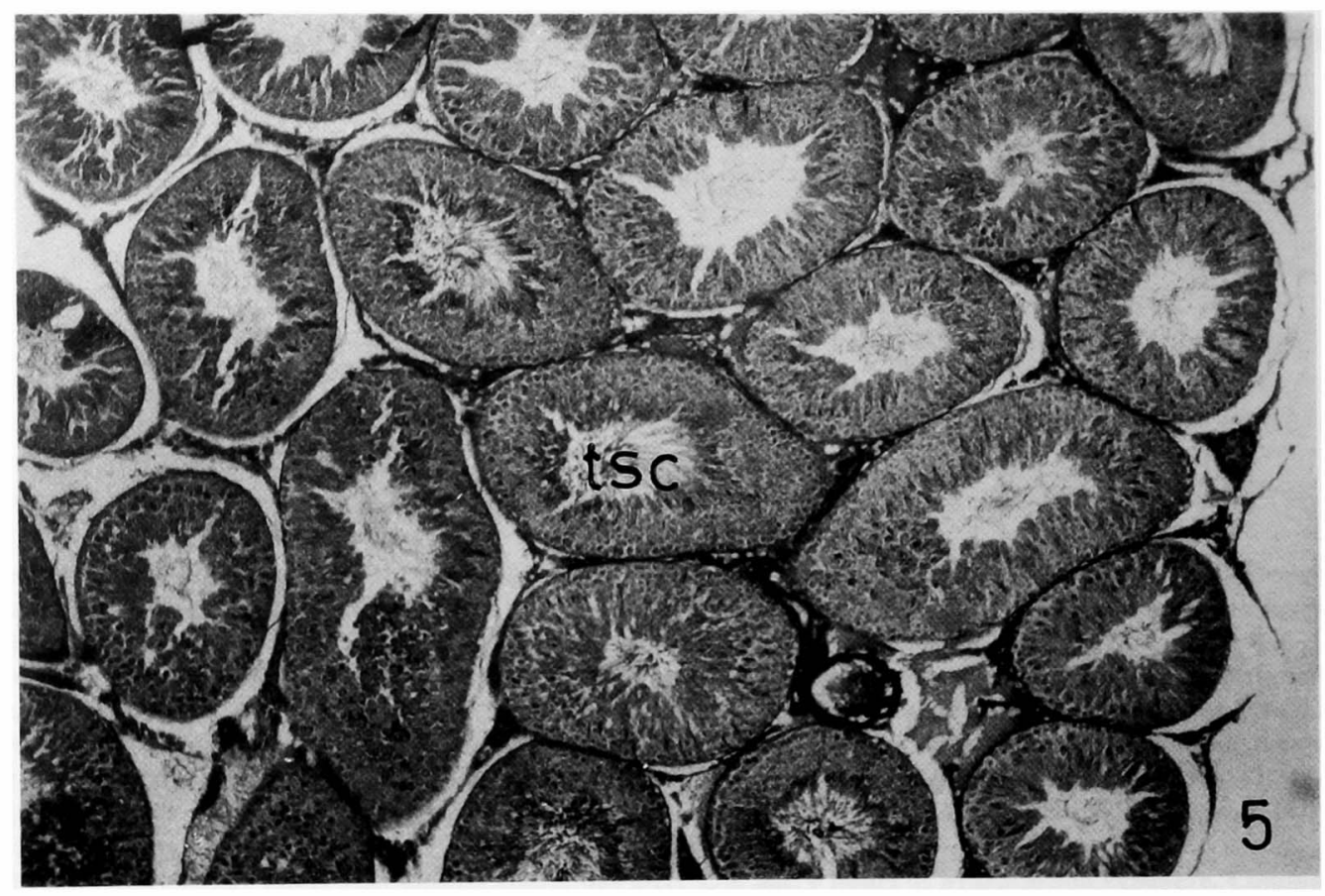

\section{Plate V}

Fig. 5. Three months after vasectomy, contralateral testis shows seminiferous tubules (tsc) similar to those observed in the control group. $\times 350$, Mallory - azan. 